\title{
E SE CAMILLO SITTE VISITASSE O RIO DE JANEIRO?
}

CLAUDIO ANTONIO SANTOS LIMA CARLOS UNIVERSIDADE FEDERAL DO RIO DE JANEIRO, RIO DE JANEIRO, RIO DE JANEIRO, BRASIL

Arquiteto e urbanista, mestre em Ciências da Arquitetura (PROARQ/FAU/UFRJ). Doutor em urbanismo pela mesma instituição. Professor do Departamento de Arquitetura e urbanismo, Universidade Rural do Rio de Janeiro (UFRRJ). E-mail: claudio.limacarlos@gmail.com

DOI

http://dx.doi.org/10.11606/issn.1980-4466.v0i22p92-117 


\section{E SE CAMILLO SITTE VISITASSE O RIO DE JANEIRO?}

CLAUDIO ANTONIO SANTOS LIMA CARLOS

\section{RESUMO}

O presente trabalho propõe a reflexão e o rebatimento, para o contexto urbano da cidade do Rio de Janeiro, de aspectos teóricos do discurso de Camillo Sitte $(1843$ - 1903) caracterizado, dentre outros pontos, pela defesa da manutenção das características originais dos entornos de monumentos. O pensamento do autor opôs-se à tendência do urbanismo racionalista, emergente na Europa da segunda metade do século XIX, de isolá-los, integrando-os aos novos traçados viários. Nessa perspectiva, foram destacados dois casos de entornos de monumentos da cidade do Rio de Janeiro: a Igreja da Candelária (Centro) e o portão principal de acesso ao Jardim da Quinta da Boavista (São Cristóvão). Os pressupostos teóricos lançados por Sitte se baseiam nas ideias lançadas pelo urbanismo desenvolvido na Europa do século XIX, antecipando um fenômeno que afetou as cidades mundiais, inclusive o Rio de Janeiro, ou seja, o isolamento de monumentos. A reflexão proposta se baseia no livro escrito por Sitte e intitulado A construção de cidades segundo seus princípios artísticos, publicado em Viena (1889). A repercussão da obra foi observada no debate teórico mundial sobre conservação de áreas urbanas, desenvolvido ao longo do século XX. Os pressupostos lançados por Sitte foram observados mais tarde nos conceitos difundidos mundialmente por teóricos e por cartas e recomendações relacionadas à conservação do patrimônio cultural das cidades, como por exemplo a Carta de Atenas (1931), a Carta de Veneza (1964), a Carta de Brasília etc. Todas elas recomendam fortemente a manutenção da morfologia original dos entornos dos monumentos.

\section{PALAVRAS-CHAVE}

Patrimônio Cultural. Urbanização. Paisagem urbana. 


\section{WHAT IF CAMILLO SITTE VISITED RIO DE JANEIRO?}

CLAUDIO ANTONIO SANTOS LIMA CARLOS

\section{ABSTRACT}

This article intends to reflect upon and debate some theoretical aspects of Camillo Sitte's (1843 - 1903) ideas, in the urban context of Rio de Janeiro, especially maintaining the original urban setting features around monuments. Camillo Sitte's discourse opposes those of a rationalist urban trend, which emerged in Europe in the second half of the 19th century, that isolated monuments and integrated them into modern urban road projects. Under this perspective, we isolated two monuments and their urban settings in Rio de Janeiro: the Candelária church and the Quinta da Boavista Garden main gate access. Sitte's assumptions are based on XIX century European urban planning development ideas that anticipated a phenomenon that affected cities from all over the world including Rio de Janeiro: monuments being isolated. The reflection proposed is based on Camillo Site works entitled City Planning According to Artistic Principles, first published in Viena in 1889 as Der Städtebau nach seinen künstlerischen Grundsätzen. The work impacted the theoretical debate on urban areas conservation throughout the world during the twentieth century. The theoretical assumptions put forth by Sitte were subsequently observed in concepts spread worldwide by theorists and charters related to the conservation of cities' cultural heritage, such as Athens Charter (1931), Venice Charter (1964), Brasília Charter (1995), and others. All these charters strongly recommended maintaining the original morphology of the monuments' surroundings.

\section{KEYWORDS}

Cultural heritage. Urbanization. Cityscape. 


\section{INTRODUÇÃO}

O presente trabalho propõe a reflexão sobre alguns aspectos teóricos do discurso de Camillo Sitte (1843-1903) e o rebatimento, para o contexto urbano e legislativo da cidade do Rio de Janeiro. Destaca-se do seu pensamento, dentre outros pontos, a defesa da manutenção das características originais das ambiências de monumentos, que se opôs à tendência do urbanismo racionalista, emergente na Europa, a partir da segunda metade do século XIX, de isolá-los e integrá-los aos novos traçados viários.

Para a realização da análise proposta foram selecionados dois casos de entornos de monumentos protegidos da cidade do Rio de Janeiro: a Igreja da Candelária (Centro) e o pórtico principal de acesso ao Jardim da Quinta da Boavista (São Cristóvão). A referida reflexão se baseou no conteúdo da obra, de autoria de Camillo Sitte, intitulada A construção de cidades segundo seus princípios artísticos ([1889]1992), publicada no Brasil somente em 1992', cuja ressonância foi observada no debate teórico mundial acerca da conservação de áreas urbanas, ocorrido ao longo do século XX. Comprovam essa influência os conceitos de ambiência e de autenticidade, dentre outros, que foram consagrados mundialmente pelas principais cartas e recomendações internacionais acerca da conservação

1. A obra foi vertida para o francês em 1902, para o russo em 1925, e para o inglês em 1945. 
do patrimônio cultural das cidades mundiais, tais como as Cartas de Atenas (1931), Veneza (1964), Brasília (1995) etc. No entanto, o seu contraponto veio a se concretizar no texto da Carta de Atenas (CIAM - 1933), que pregou justamente o inverso, ou seja, o isolamento dos mais significativos monumentos das cidades como a única solução para preservar suas existências, em face dos novos traçados viários.

No Rio de Janeiro, observa-se que as intervenções executadas pela prefeitura sobre o seu tecido urbano a partir dos anos 1940 seguiram os princípios urbanísticos racionalistas criticados por Sitte, especialmente o que consistia na submissão completa dos entornos originais de monumentos ao desenho das novas vias expressas, voltadas à satisfação das demandas viárias e imobiliárias da cidade. As aberturas da Avenida Presidente Vargas (Candelária) e da Rua General Herculano Gomes (Quinta da Boavista) materializaram a adoção desses princípios pela agenda do planejamento urbano da cidade, acarretando consequências no mínimo questionáveis, que o presente trabalho busca abordar.

\section{ALGUNS ASPECTOS IMPORTANTES DA OBRA DE CAMILLO SITTE}

Em função dos objetivos estabelecidos, o presente trabalho destaca da obra de Sitte alguns importantes aspectos relacionados ao modelo de cidade surgido na segunda metade do século XIX, bem como ao tipo de tratamento dispensado aos seus monumentos, face às adaptações formais e funcionais emergentes na modernidade.

Nesse contexto, Camillo Sitte dispensou grande atenção à manutenção da dimensão estética das cidades sob o risco de perda de seus princípios artísticos. Percebeu que a imposição de novos padrões construtivos dotados de novas tecnologias e preocupados apenas em atender demandas econômicas, produziria rapidamente a ruptura da cultura urbana existente, apagando tradições construtivas e induzindo à monotonia e uniformidade paisagística das cidades. O período por ele vivido foi marcado pelo início de uma nova lógica produtiva e pela construção de um novo contexto social que impuseram às cidades uma acelerada expansão, originando na arquitetura e no urbanismo do século XX um tipo de fenômeno caracterizado pela predominância de um discurso oficial bastante monolítico e simplista. Nele, prevaleceu sempre o dogma funcionalista que submetia a forma à 
dependência das demandas advindas dos processos sociais e econômicos que lhes davam suporte (SANTOS, 1988, p. 25).

Sendo assim, propôs uma maneira de transpor a essência compositiva das cidades antigas para o contexto urbano e respectivas demandas construídas na modernidade, sem, no entanto, defender seu congelamento ou cópia. Assim, seria possível a formulação de alternativas compositivas capazes de evitar aquilo que identificou como duas das mais marcantes características das cidades modernas emergentes no século XX: a confusão e a monotonia. A antevisão de Sitte dos efeitos negativos das soluções racionalistas que posteriormente à sua morte foram adotadas de forma quase consensual em cidades mundiais, possibilitaram frequentes comparações teóricas entre ele e Le Corbusier, cujo pensamento floresceu muito tempo depois da sua morte, ocorrida em $1903 .^{2}$

Camillo Sitte também destacou a falta de autenticidade representada, segundo ele, pela prática recorrente no século XIX de "copiar" estilos históricos e adaptá-los indiscriminadamente às novas tipologias arquitetônicas emergentes na modernidade. Seguindo o mesmo raciocínio utilizado para a escala urbana, Sitte defendia a manutenção da essência das soluções compositivas da arquitetura do passado, recomendando aos planejadores das cidades livrarem-se “(...) do sistema moderno dos conjuntos de casas regularmente alinhadas; salvar, na medida do possível, o que resta das cidades antigas; e aproximar sempre mais nossas criações atuais do ideal dos modelos antigos". (CHOAY, 1979, p. 206) ${ }^{3}$

No entanto, o ponto mais importante da obra de Camillo Sitte para a reflexão proposta diz respeito ao tratamento dispensado aos monumentos históricos, pela urbanística emergente na modernidade, que estabeleceu como solução para o conflito gerado entre a renovação e a preservação, o seu isolamento e adaptação aos novos traçados. A premissa projetual

\footnotetext{
2. Cabe destacar um importante aspecto relacionado à edição francesa, datada de 1902, que trouxe alterações introduzidas pelo arquiteto Camile Martin, seu editor. Elas consistiram da retirada de partes relacionadas à cidade barroca e um capítulo escrito por Martin, que expandiu as observações de Sitte, originalmente restritas às praças, ao traçado das ruas. Martin destacou a morfologia sinuosa das ruas e praças medievais como as formas mais adequadas às cidades.

3. Segundo Sitte, "Os modelos dos antigos devem reviver hoje, e não como cópias conscienciosas; é examinando o que há de essencial em suas criações e fazendo sua adaptação às circunstâncias modernas que podemos atirar, num solo aparentemente estéril, um grão capaz de germinar de novo". (CHOAY, 1979, p. 215)
} 
apontou para o deliberado descarte dos entornos tradicionais mutilando irreversivelmente os respectivos tecidos, atentando assim contra a memória arquitetônica e a autenticidade das paisagens das cidades. Sobre esse importante aspecto da conservação urbana, presente na obra de Sitte, e o seu rebatimento para o caso do Rio de Janeiro, o presente trabalho irá debruçar-se brevemente.

\section{A VIZINHANÇA DE MONUMENTOS}

Entende-se que Sitte percebeu, a partir do seu olhar sobre as cidades europeias, o que viria a ser uma problemática urbana mundial que destacou o antagonismo estabelecido entre as intervenções com fito de "modernização" e a necessidade de conservação da sua herança cultural material. Mesmo tendo adotado como referência a conjuntura urbana europeia, os conceitos por ele lançados relacionados à vizinhança de monumentos e a necessidade da manutenção da essência compositiva dos contextos urbanísticos e arquitetônicos tradicionais das cidades, representaram uma contribuição relevante para o debate da questão mundial da conservação urbana.

Sitte, ao identificar as ameaças impostas pela modernidade às paisagens urbanas tradicionais europeias, antecedeu em algumas décadas importantes questões relacionadas à construção do debate mundial acerca da sua própria conservação, desenvolvido somente ao longo do século seguinte. Essas questões incidiriam não apenas no contexto das cidades européias, mas também no ambiente urbano das cidades mundiais, especialmente as sul-americanas, dentre elas o Rio de Janeiro.

Nesse sentido, destacou como fundamental a manutenção da relação original estabelecida entre a arquitetura, principalmente as de escala monumental, e seus entornos, declarando-se frontalmente contrário ao princípio urbanístico do isolamento de monumentos, decorrente da sua inserção em novos e modernos traçados urbanos. Destacou a importância do respeito aos esquemas originais de implantação das edificações antigas e criticou de forma contundente a tendência da "urbanística moderna" de isolar construções antigas, para destacá-las ou alinhá-las aos eixos das novas ruas, conforme aconselhava Reinhard Baumeister em seu manual de construção urbana. Segundo ele, as construções antigas deveriam "ser preservadas, mas desimpedidas e restauradas" (SITTE, 1992, p.46). Nesse 
sentido, denunciou o que denominou de "fenômeno" que corria em toda parte, apontando o seu "refinamento" quando a premissa projetual impunha o isolamento de antigos portões de burgos ou pórticos em geral. Em função disso, ironizou o efeito gerado pelo referido partido, adotado em alguns exemplos por ele analisados em cidades européias, afirmando: "De fato, uma coisa muito bonita, isso de um portão que não se atravessa, mas em torno do qual se passeia”. (SITTE, 1992, p. 46) (figuras 1 e 2)

Os esquemas de implantação, funções e relações originais do monumento com seus respectivos entornos, segundo Sitte, constituíam-se em entidades inseparáveis. Por outro lado, os aspectos arquitetônicos e urbanísticos tradicionais das cidades estabeleciam relevantes "lições do passado" que poderiam e deveriam orientar intervenções propostas por arquitetos no presente. Sitte, conforme já destacado, não propunha cópias, mas a ressonância da essência artística destas, no presente e no futuro das cidades.

FIGURA 1

Porta citadina da cidade de Lubbeck Alemanha, citada por Sitte como um exemplo de isolamento inadequado

de monumentos. (SITTE, 1992, p. 46) Fonte: <http://pelaslentesdoturismo. blogspot.com.br/> Acesso em: 20 nov. 2016.

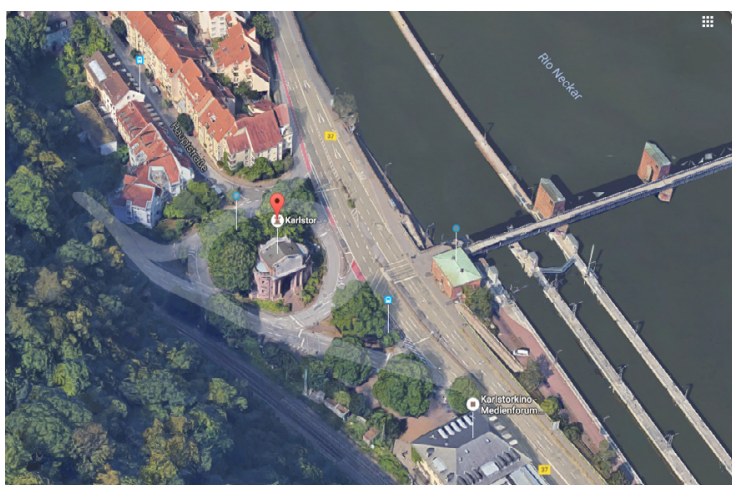

FIGURA 2

Karlstor, Heildelberg, Alemanha, citada por Sitte como exemplo de isolamento inadequado de monumentos. (SITTE, 1992, p. 46) Fonte: <https:// www.google.com. $\mathrm{br} / \mathrm{maps} / \mathrm{place} /$ Karls tor/@49.4139979,8. 7238142,449a,20y 270h,41.57>. Acesso em 20 nov. 2016

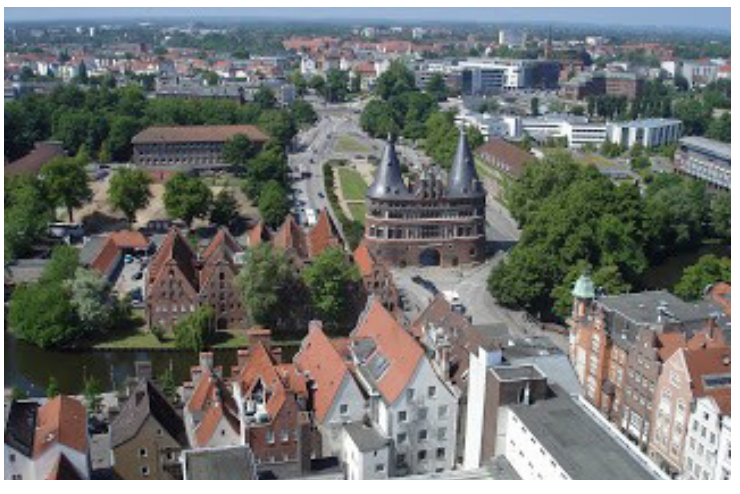




\section{A OBRA DE SITTE E A DISCUSSÃO MUNDIAL DO TEMA DA CONSERVAÇÃO URBANA}

É importante destacar que, apesar das críticas de Sitte, a tendência de isolamento de monumentos foi consagrada mundialmente cerca de três décadas após sua morte, na Carta de Atenas (CIAM - 1933), face às necessidades prementes de preservação do patrimônio cultural das cidades. O referido documento teve seu contraponto dado por outro de igual envergadura internacional, a também denominada Carta de Atenas (1931 - Escritório Internacional dos Museus Sociedade das Nações), que recomendou justamente o inverso.

Choay (RIEGL, 1984, p. 8), diante do conteúdo dos dois documentos, elegeu-os como os dois principais paradigmas urbanísticos que caracterizariam a ambivalência do pensamento contemporâneo sobre as cidades ocidentais. Enquanto a Carta de Atenas (1931) recomendou que “(...) na construção dos edifícios, o caráter e a fisionomia das cidades, sobretudo na vizinhança dos monumentos antigos, cuja proximidade deve ser objeto de cuidados especiais. Em certos conjuntos, algumas perspectivas particularmente pitorescas devem ser preservadas"; a outra Carta de Atenas (1933) recomendou, dentre outras medidas, o isolamento de partes únicas que constituam "uma lembrança ou um valor real" para a cidade. As duas premissas vieram a se constituir, ao longo do século XX, em objeto de debates mundiais acerca da conservação do patrimônio cultural urbano. Os pressupostos estabelecidos pela Carta de Atenas (1931) foram consolidados e ampliados conceitualmente, em nível mundial, a partir do Congresso de Arquitetos ocorrido, em 1964, na cidade de Veneza. O evento originou documento conclusivo de mesmo nome da Cidade italiana, que ampliou o entendimento de monumento histórico, inserindo-o na categoria de objeto plural, composto não somente pela "criação arquitetônica isolada", mas também pelo sítio urbano ou rural que dá testemunho de uma civilização particular, de uma evolução significativa ou de um acontecimento histórico. A Carta de Veneza (1964) inseriu no rol de objetos passíveis de conservação, além das grandes criações, as obras modestas, que tenham adquirido, com o tempo, uma significação cultural.

A Carta de Veneza (1964) também destacou que a "conservação de um monumento implica a preservação de um esquema em sua escala. Enquanto subsistir, o esquema tradicional será conservado, e toda construção nova, 
toda destruição e toda modificação que possam alterar as relações de volumes e de cores serão proibidas". Mais à frente, as Recomendações de Nairóbi (UNESCO, 1976) definiram o conceito de ambiência como o "quadro natural ou construído que influi na percepção estática ou dinâmica desses conjuntos, ou a eles se vincula de maneira imediata no espaço, ou por laços sociais, econômicos ou culturais". No tópico n. 29, destacou que: "não se deveria autorizar o isolamento de um monumento através da supressão de seu entorno; (...)”. O Documento Regional do Cone Sul sobre autenticidade (BRASÍLIA, 1995), por sua vez, recomendou que: “(...) É imprescindível o equilíbrio entre o edifício e seu entorno, tanto na paisagem urbana quanto na rural. Sua ruptura seria um atentado contra a autenticidade". O debate estabelecido ao longo do século $\mathrm{XX}$, relacionado à conservação de monumentos no contexto urbano das cidades, comprovou que Sitte anteviu, com antecedência de décadas, alguns dos principais problemas que incidiriam sobre a questão.

A sua crítica ao isolamento de monumentos seria confirmada a partir de resultados obtidos em intervenções urbanísticas que visaram à implantação de sistemas viários, ocorridas em diversas cidades do mundo, inclusive e especialmente a do Rio de Janeiro. Por outro lado, observa-se que o pensamento de diversos autores ao longo do século XX, voltados à revisão das premissas teóricas generalizantes consolidadas pelos CIAM, retomou algumas das principais questões do discurso de Camillo Sitte, como o resgate e o respeito pelas soluções urbanísticas e arquitetônicas tradicionais das cidades, identificados a partir do estudo e da análise de seus respectivos contextos históricos.

Sob este viés, destacou-se Gustavo Giovannoni (1873 - 1943), autor da inédita terminologia "patrimônio urbano", utilizada na obra Vecchie città ed edilizia nuova (1931). ${ }^{4}$ Giovannoni, além de consolidar a reverência ao legado urbano, destacando seu papel de referência compositiva obrigatória na expansão das cidades já detectado por Sitte, em 1889; ampliou seu entendimento integrando-o a uma concepção geral de organização do território acrescentando ao valor histórico o que Choay (2001, p. 194) denominou de valor de uso. Mais tarde, Aldo Rossi (1931-1997), em sua obra $A$ arquitetura das cidades (1966), retomou a ideia de contemplação 
obrigatória de componente histórico no planejamento e estudo das cidades contemporâneas, dentre outros aspectos teóricos que se aproximam do pensamento de Sitte. Acrescentaram-se a esse contexto teórico as contribuições de Henri Lefebvre (1901-1991) e de G. C. Argan (1909-1992), que desenvolveram estudos sobre a cidade orientados pela sua associação à categoria de produto artístico.

Mais recentemente, os conceitos de lugar e o de espírito do lugar, desenvolvidos por autores como Norberg Schulz (1984), dentre outros, foram consagrados mundialmente por intermédio da Declaração de Quebec (2008) que estabeleceu os aspectos tangíveis e intangíveis como elementos essenciais a serem percebidos pela prática da conservação de sítios urbanos. Dentre os aspectos intangíveis citados, encontra-se o "conhecimento tradicional" que, sem dúvida, abrange as formas tradicionais de construir e edificar lugares. ${ }^{5}$

Cabe também citar a corrente urbanística New Urbanism que marcou uma posição contrária aos cânones urbanísticos difundidos pelos CIAM, apropriando-se de vários aspectos relacionados ao pensamento regionalista derivado de vários autores, inclusive Camillo Sitte, apesar de não fazer qualquer tipo de referência ou citação. A "nova" corrente estabeleceu regras para um "urbanismo ideal", calcadas na escala humana, priorização da percepção da paisagem urbana pelo pedestre, valorização de espaços públicos de convivência comunitária e, principalmente, no aprendizado com as lições do passado. Nesse sentido, A. Duany (1998), uma das lideranças do movimento New Urbanism na América Latina, destaca que os arquitetos e urbanistas "em lugar de eternamente inventar e experimentar" deveriam estudar os modelos que "funcionam" e humildemente tratar de desenvolvê-los. Observar o que funciona bem e organizar para as pessoas "o que não é uma invenção nossa: estamos recriando um processo que previamente

5. “(...) o espírito do lugar é composto por elementos tangíveis (sítios, edifícios, paisagens, rotas, objetos) bem como de intangíveis (memórias, narrativas, documentos escritos, festivais, comemorações, rituais, conhecimento tradicional, valores, texturas, cores, odores, etc.) e que todos dão uma contribuição importante para formar o lugar e lhe conferir um espírito, declaramos que o patrimônio cultural intangível confere um significado mais rico e mais completo ao patrimônio como um todo, e deve ser considerado em toda e qualquer legislação referente ao patrimônio cultural e em todos os projetos de conservação e restauro para monumentos sítios, paisagens, rotas e acervos de objetos." (Carta de Quebec, Icomos, 2008. Disponível em: <http://www.icomos.org/quebec20o8/quebec_declaration/pdf/GA16_Quebec_Declaration_Final_PT.pdf>. Acesso em: 20 jul. 2016) 
mostrou ser exitoso". Sem dúvida Sitte endossaria essas proposições teóricas, cerca de mais cem anos após sua morte, o que confirma a importância do seu pensamento na contemporaneidade.

\section{BREVES CONSIDERAÇÕES SOBRE A LEGISLAÇÃO DE PATRIMÔNIO CULTURAL E A CIDADE DO RIO DE JANEIRO NA PRIMEIRA METADE DO SÉCULO XX}

A análise dos contextos culturais que abrigaram a criação das legislações vigentes no país e na cidade do Rio de Janeiro se faz necessária para um melhor entendimento dos dois casos destacados pelo presente estudo. A partir dela torna-se possível avaliar as reais intenções do Estado no cumprimento ou não dos parâmetros previamente estabelecidos.

Observou-se no Brasil, a partir dos anos 1920, alguns avanços no campo da proteção do patrimônio cultural, momento em que alguns estados e municípios além de São Paulo, já desenvolviam experiências de criação de órgãos públicos voltados a este fim. ${ }^{6}$ Muito contribuiu para esse cenário a atmosfera nacionalista emanada pelos movimentos neocolonial e modernista brasileiros, cujos valores foram incorporados pelo Estado Novo de Vargas (1930-1945), preocupado com a construção de nossa identidade a partir de nossas raízes culturais, capazes de cativar intelectuais voltados ao projeto de modernidade nacional.

A partir de 1931, o contexto de valorização das raízes culturais brasileiras foi fortalecido pelas preocupações com a preservação da herança cultural das cidades, emanadas pela Carta de Atenas. Observam-se diversos fatos que confirmam essa tendência no país como, por exemplo, a proteção da cidade Ouro Preto (1933) , a edição da primeira Constituição brasileira que transferiu ao Estado a atribuição de preservar o patrimônio cultural brasileiro (1934) e a edição da primeira legislação de proteção do patrimônio cultural brasileiro, o Decreto-Lei n. 25, de 1937, que ainda vigora integralmente. No mesmo ano, a gestão do Presidente Getúlio Vargas também criou

\footnotetext{
6. O município de Recife, por exemplo, em 1927 já possuía seu próprio serviço de patrimônio cultural, idealizado por Gilberto Freire. Os direitos da concepção do órgão foram cedidos por Freire, à Mário de Andrade, originando, em 1937, o então Serviço de Patrimônio Histórico e Artístico Nacional - SPHAN (atual Iphan). (Mourão apud Prefeitura, 1990, p. 5)

7. Pelo Decreto n. 22.928, publicado em 12 de julho, de 1933.
} 
o primeiro órgão de patrimônio cultural do país denominado inicialmente Serviço do Patrimônio Artístico e Histórico Nacional (Sphan) e atualmente Instituto do Patrimônio Artístico e Histórico Nacional (Iphan).

No Rio de Janeiro, o início do século XX foi marcado por radicais intervenções urbanísticas voltadas, entre outros aspectos, ao aperfeiçoamento da mobilidade urbana a partir do seu centro. Um novo projeto viário foi criado com a intenção de ligá-lo, por intermédio de vias expressas, aos bairros da zona sul, ao novo porto da cidade e à zona norte, em atendimento aos novos vetores de expansão da intensificação da ocupação da cidade. Nesse contexto surgiram grandes avenidas, como as avenidas Central, Beira Mar, Rodrigues Alves e o eixo constituído pelas Ruas Estácio de Sá, Mem de Sá e Salvador de Sá (ligação centro-norte).

No período de 1940 a 1960, o automóvel consolidou-se como a principal forma de transporte intraurbano, consagrando o "planejamento radical" como forma de intervenção no tecido da cidade. ${ }^{8}$ Sob esse contexto, outras intervenções viárias que incluíram novas e grandes avenidas, além de viadutos e elevados, foram realizadas. Com relação aos dois paradigmas enunciados pelas duas Cartas de Atenas, anteriormente citados por Choay, viu-se, na cidade do Rio de Janeiro, o triunfo das premissas projetuais difundidas pela Carta de Atenas (1933), especialmente em relação à conservação de monumentos, considerada possível somente quando a sua adaptação e "alinhamento" aos novos traçados urbanos fosse viável.

As grandes intervenções observadas na cidade durante o referido período, que chegaram a poupar algum monumento, só o fizeram porque foi possível a adoção da estratégia do isolamento e alinhamento, criticada enfaticamente por Sitte. O engenheiro José de Oliveira Reis, que atuou intensamente à frente da prefeitura nesse período, definiu bem o que era entendido como urbanismo na sua época, afirmando que este consistia do "conjunto de regras aplicadas ao melhoramento da edificação, do

8. Alison Ravetz (RELPH, 2002, p. 129-130) classificou como "planejamento radical" a atitude de “(..) planejar sem quaisquer limitações físicas ou históricas”. Relph (idem, p. 130), nesse sentido, destaca que o "planejamento radical" integrou os sonhos de todos os construtores urbanos desde que Haussmann construiu avenidas através de Paris, no início dos anos 1850, ressurgindo com grande intensidade no segundo pós-guerra, em um cenário favorável de destruição generalizada das cidades europeias. Na perspectiva de minimizar ao máximo possíveis obstáculos a “(...) ideia era que pouco ou, possivelmente nada, do que era antigo merecia ser preservado ou reproduzido". 
arruamento, da circulação e do descongestionamento da circulação pública". Buscava-se sempre "a remodelação, a extensão e o embelezamento de uma cidade levados a efeito mediante um estudo metódico da geografia humana e da topografia, sem descuidar das soluções financeiras". (FREIRE; OLIVEIRA, 2008, p. 20)

Sob esse contexto urbanístico, o presente trabalho buscou analisar criticamente os resultados obtidos a partir da construção de dois eixos viários em que estas premissas foram integralmente adotadas pela administração da Cidade. São elas: a construção da Avenida Presidente Vargas-Centro, cujo traçado incorporou e isolou a Igreja da Candelária; e a construção da Rua General Herculano Gomes, cujo traçado isolou em uma rotunda o pórtico de entrada principal do Jardim da Quinta da Boavista - Bairro de São Cristóvão. A análise dos dois casos buscará relacioná-los aos conceitos lançados por Camillo Sitte acerca dos inconvenientes causados pelo isolamento de monumentos, fato que possibilitou verificar a validade de seu pensamento para casos que extrapolam as fronteiras das cidades da modernidade europeia, foco original de sua obra.

Sendo assim, os dois casos aqui abordados (Pórtico da Quinta da Boavista e Igreja da Candelária) configuram exemplos de tombamentos federais cujas intervenções propostas foram devidamente analisadas e aprovadas pelos órgãos federais de patrimônio cultural. Mediante esses dois casos também é possível constatar, especialmente no caso da Igreja da Candelária, as contradições estabelecidas pelo autoritarismo de Vargas, que, por um lado, preserva e valoriza a memória arquitetônica do país, mas, por outro, também a destrói, submetendo-a aos padrões do urbanismo rodoviarista e comprometido com as leis do mercado imobiliário. Cabe ressaltar, dentre outros, a intensa mobilização de técnicos e estudiosos da arte e da arquitetura ocorrida em 1941 contra a demolição das igrejas de São Pedro dos Clérigos e de Bom Jesus do Calvário. As duas igrejas eram protegidas pelo tombamento federal desde 1938 e foram destombadas e demolidas em 1943 para viabilizar a construção da Avenida Presidente Vargas. ${ }^{9}$ Lyra (2007), acerca da demolição, relata que: 
O instituto do tombamento, criado pelo decreto-lei n. 25, de 30 de novembro de 1937, surgiu como o instrumento jurídico capaz de atenuar a destruição do patrimônio construído. Entretanto, quatro anos depois, os planos de abertura de uma outra avenida levaram o presidente Getulio Vargas a promulgar decreto criando a figura do "cancelamento do tombamento de bens do Patrimônio Histórico e Artístico Nacional". A finalidade imediata era legitimar a demolição das igrejas do Bom Jesus do Calvário e São Pedro dos Clérigos, além da mutilação do Campo de Santana (...).

Por outro lado, ao ler o texto do Decreto-lei 25 é possível também identificar alguns aspectos importantes para o entendimento de algumas razões legais que possivelmente embasaram a autorização das obras no entorno da Igreja da Candelária. O Artigo 18 expressa cuidados com o entorno do monumento estabelecendo que, sem a prévia autorização do órgão de patrimônio cultural, “(...) não se poderá, na vizinhança da coisa tombada, fazer construção que lhe impeça ou reduza a visibilidade, nem nela colocar anúncios ou cartazes, sob pena de ser mandada destruir a obra ou retirar o objeto (...)". Realmente, ao resgatarem-se as justificativas do engenheiro José de Oliveira Reis, entende-se perfeitamente que a demolição integral do entorno da Igreja da Candelária - comparado a "pólipos" - ironicamente teve respaldo legal do Decreto Lei n. 25/37, atendendo plenamente aos princípios da otimização da visibilidade do monumento. No entanto, no caso da intervenção executada nos jardins da Quinta da Boavista, não é possível sequer observar uma tentativa de respaldar legal e tecnicamente a intervenção, uma vez que o próprio Decreto-Lei 25 recomenda que as “(...) coisas tombadas não poderão, em caso nenhum, ser destruídas, demolidas ou mutiladas, (...)”.

Como contraponto à legislação federal, ao longo da década de 1980 a legislação urbana do Rio de Janeiro apresentou preocupações mais alinhadas com a evolução das questões e consensos mundiais acerca da conservação do caráter das cidades, verificada na segunda metade do século XX. Nesse período, observou-se a publicação de uma sucessão de legislações que,

um exemplo extraordinário do barroco derivado da escola italiana. Foram inúteis os esforços do Sphan para salvá-la. Pensou-se até em congelar o solo e transportá-la para um outro local, mas o custo da operação era altíssimo. Em 8 de janeiro de 1943, o tombamento foi cancelado e um ano depois a igreja foi demolida. Dela só restam fotografias". 
gradativamente, extrapolaram os limites físicos do monumento, impondo restrições aos direitos de propriedade também aos seus entornos. Tais preocupações surgiram timidamente em 1980, com a publicação da Lei Municipal n. 166, que estabeleceu parâmetros gerais da aplicação do tombamento no nível administrativo municipal. ${ }^{\circ} \mathrm{O}$ texto estabeleceu que o órgão responsável pela conservação do bem cultural tombado pode estabelecer restrições ao seu entorno desde que haja a iminência de ato que de alguma forma altere, dentre outros pontos, a visibilidade do bem tombado. ${ }^{11}$ Em 1988, surgiu a primeira legislação preocupada em conservar áreas urbanas e também naturais (Decreto 7.612), a Área de Proteção Ambiental (APA).

O texto do Plano Diretor Decenal da Cidade (1992) transformou a APA em Área de Proteção do Ambiente Cultural (APAC) passando a ser um instrumento específico de proteção de áreas urbanas, estabelecendo outros graus de proteção, além do tombamento, bem como a obrigatoriedade da conservação de sua malha urbana, esquemas de implantação, dentre outros aspectos urbanísticos. O Plano Diretor ainda previu a possibilidade do estabelecimento de áreas de entorno de bens tombados, com vistas à proteção da sua ambiência. Em 2011, após atraso de nove anos, a revisão de seu texto consolidou as citadas diretrizes anteriores, bem como introduziu um novo mecanismo de proteção de monumentos, visando proteger cautelarmente o seu entorno, ou seja, o automático estabelecimento de uma área de influência correspondente a um raio de 200 metros a partir dos seus limites externos.

Certamente nos dias atuais, mais democráticos, dotados de leis mais abrangentes às demandas de conservação de sítios históricos e entornos de bens tombados, as citadas obras sofreriam, no mínimo, maior resistência e questionamentos à sua plena execução. No entanto, essas intervenções nos dão um claro e didático testemunho dos efeitos nocivos do planejamento radical, que inclui em seu repertório o isolamento e alinhamento de monumentos aos novos traçados impostos à cidade de forma invariavelmente autoritária.

10. Há no Brasil três esferas administrativas que são a federal, a estadual e a municipal. A atribuição de tombar é estendida aos poderes executivos das três instâncias.

11. Art. $9^{\circ}$ - Decretado o tombamento, compete ao Conselho Municipal de Proteção do Patrimônio Cultural do Rio de Janeiro pronunciar-se quanto: (...) c) à prática de qualquer ato que de alguma forma altere a aparência, a integridade estética, a segurança ou a visibilidade do bem tombado pelo Município. 


\section{A IGREJA DA CANDELÁRIA E A AVENIDA PRESIDENTE VARGAS}

A partir dos anos 1940, a malha urbana do centro da cidade foi significativamente marcada pela construção da Avenida Presidente Vargas, obra emblemática do governo ditatorial do Presidente Getúlio Vargas (1930-1945) na então capital do Brasil. A intervenção visou melhorar a ligação viária entre os bairros da zona norte e o centro, sendo que isso ocasionou a demolição de 525 prédios, durante os mais de três anos necessários à sua construção (19 abr. 1941-7 set. 1944) (ABREU, 1987, p. 113-114). Esses prédios distribuíam-se ao longo de seu leito, de pouco mais de 4.000 metros de comprimento por cerca de 80 metros de largura (REIS, 1994, p. 8). A intervenção urbanística, em que pese seu grande impacto na paisagem do centro da cidade, também gerou massa de desabrigados, que veio, assim como as demais intervenções ocorridas no centro, contribuir para o agravamento da questão social da cidade.

A construção da avenida sacrificou, além das mais de 500 edificações citadas, que configuravam um conjunto arquitetônico característico da virada do século XIX para o século XX, expressivo grupo de outras edificações com escala monumental e igualmente significativas para a paisagem e a memória carioca, tais como o Paço Municipal (sede administrativa da prefeitura da cidade), a Igreja de São Pedro dos Clérigos, exemplar raro de arquitetura religiosa barroca da cidade, dotada de planta elíptica; a Igreja do Bom Jesus do Calvário, a Igreja de São Domingos, além de trecho significativo do Campo de Santanna, todos localizados no "miolo" da avenida. Em face da destruição causada pelas obras de abertura da nova avenida, o único monumento a ser poupado foi a Igreja de Nossa Senhora da Candelária, por condições bastante peculiares. Cabe destacar que a edificação já era protegida, desde 1938, por tombamento promovido pelo próprio governo federal. No entanto, a sua permanência foi explicada por outros motivos mais "convincentes" à época. Segundo o engenheiro José de Oliveira Reis (1994, p. 8), coordenador das obras para construção da avenida, a manutenção do monumento foi justificada também pela "sua arquitetura monumental e majestosa", mas, sobretudo, "pela coincidência de ficar no eixo da avenida". Ainda segundo ele, "antes da abertura dessa avenida, a Igreja da Candelária estava emparedada por edificações a ela aderidas como 'pólipos', (...). Foi preciso a Prefeitura desapropriar, pagar e demolir esses prédios para que a monumental obra arquitetônica aparecesse". 
Observa-se, na justificativa do engenheiro, total submissão aos preceitos teóricos da Carta de Atenas (1933), que por sua vez referendam a tendência da premissa projetual de isolamento de monumentos, difundida por Reinhard Baumeister, dentre outros, e criticada duramente por Camillo Sitte. O monumento foi inserido em uma praça retangular (Praça Pio X), definida por conjunto de prédios de arquitetura modernista com doze pavimentos ${ }^{12}$, enquanto os demais trechos da avenida receberam prédios com gabarito de 22 pavimentos. O artifício, segundo Reis (1994, p. 9), foi adotado com o intuito de não "esmagar" a igreja. No entanto, a intervenção alterou completamente a relação volumétrica do monumento com seu entorno, deixando-o completamente isolado. $\mathrm{O}$ partido adotado deu à igreja ênfase exacerbada à função de elemento de composição da paisagem artificialmente criada, muito explicada pela sua localização, conforme já destacado.

A intervenção urbanística alterou drasticamente a relação volumétrica anteriormente existente entre a igreja e seu entorno original, formado por edificações com altura bem inferior, com dois pavimentos em média (figuras 3, 4 e 5). Antes da intervenção, a Igreja da Candelária, em função de sua escala, era a referência visual na paisagem do lugar, sendo visível a grandes distâncias e acessível aos passantes que a alcançavam por intermédio de ruas estreitas. Após a construção da Avenida Presidente Vargas, oculta pela significativa massa de prédios construída, o monumento tornou-se visível ao observador apenas da Praça Pio X e do leito da própria Avenida, até grandes distâncias.

Em função disso, as condições de acesso e de fruição do monumento por parte de pedestres ficaram sensivelmente prejudicadas, tendo em vista o "ilhamento" causado por vias expressas com grande tráfego de veículos, inclusive ônibus e caminhões (Figura 4). Sacrificou-se a condição de local de fácil acesso em prol da função de um mero elemento de composição paisagística. A igreja passou a ser um prédio cuja prioridade não é entrar e sim circundar e ser observado à distância pelo passante, talvez dissesse Camillo Sitte, caso visitasse o Rio de Janeiro.

\footnotetext{
12. Dentre eles encontra-se o edifício-sede do extinto Banco Boavista, projetado por Oscar Niemeyer em 1946 e o edifício-sede do também extinto Banco Aliança, projetado por Lúcio Costa em 1956.
} 
FIGURA 3

Vista da Igreja da Candelária e parte de seu entorno antes da abertura da Avenida Presidente

Vargas. Postal. A.

Ribeiro, Travessa

Ambrosina, 25

Aldeia Campista, Rio de Janeiro, [c. 1910]

Fonte: <http://

www.caravelas.com

pt/lugares.html>

Acesso em: 21 nov.

2016.

FIGURA 4

Praça Pio X, com a Igreja da Candelária ao Centro.
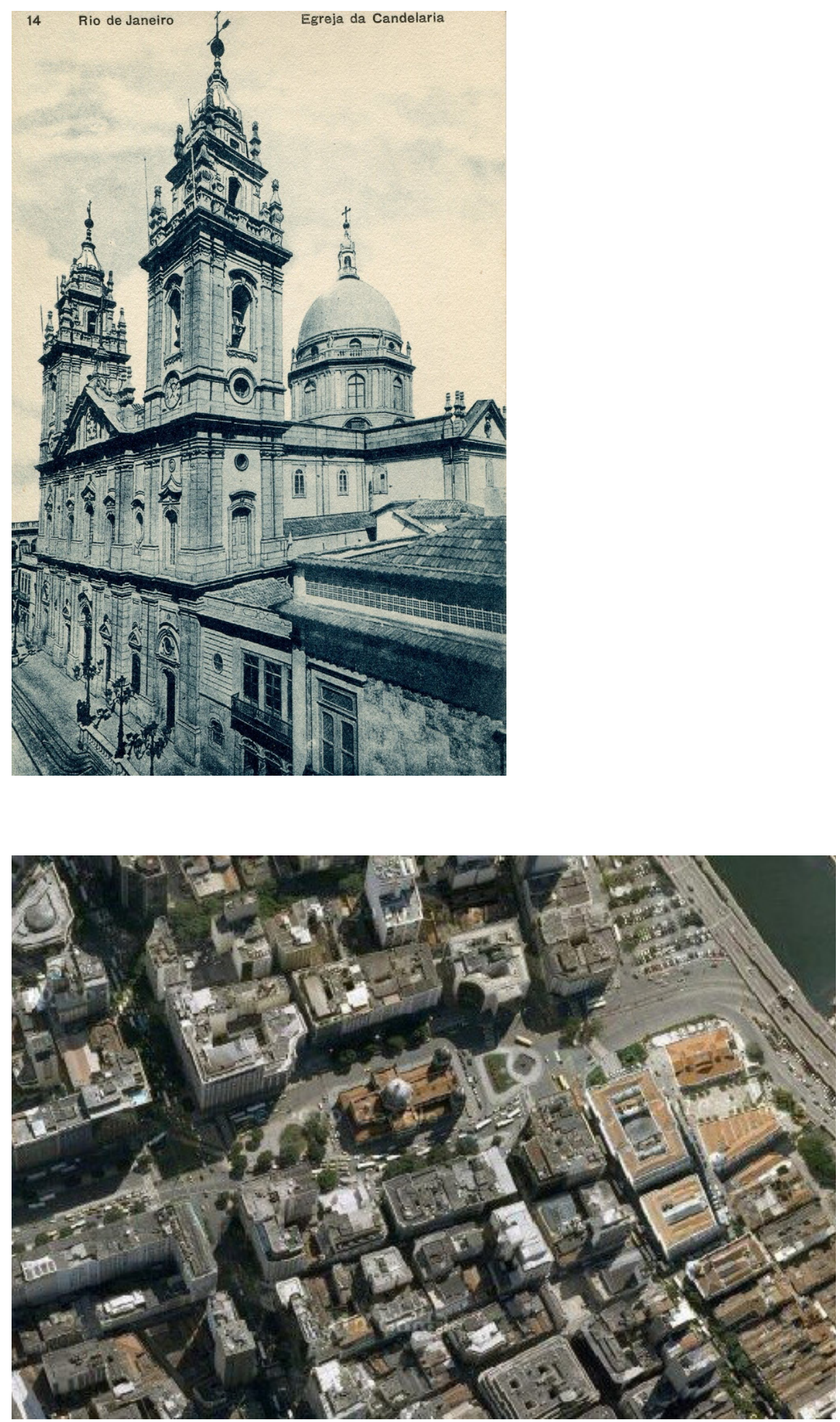
FIGURA 5

Vista do Centro da

Cidade obtida da Baía de Guanabara de onde se percebe a Igreja da Candelária que rompe a silhueta proporcionada pelas edificações existen-

tes anteriormente à construção da Avenida Presidente

Vargas. Fonte:

http://literaturaeriodejaneiro.blogspot. com.br200302mapas-antigos-do-rio-de-janeiro html-janeiro_html. Acesso em 21: nov. 2016

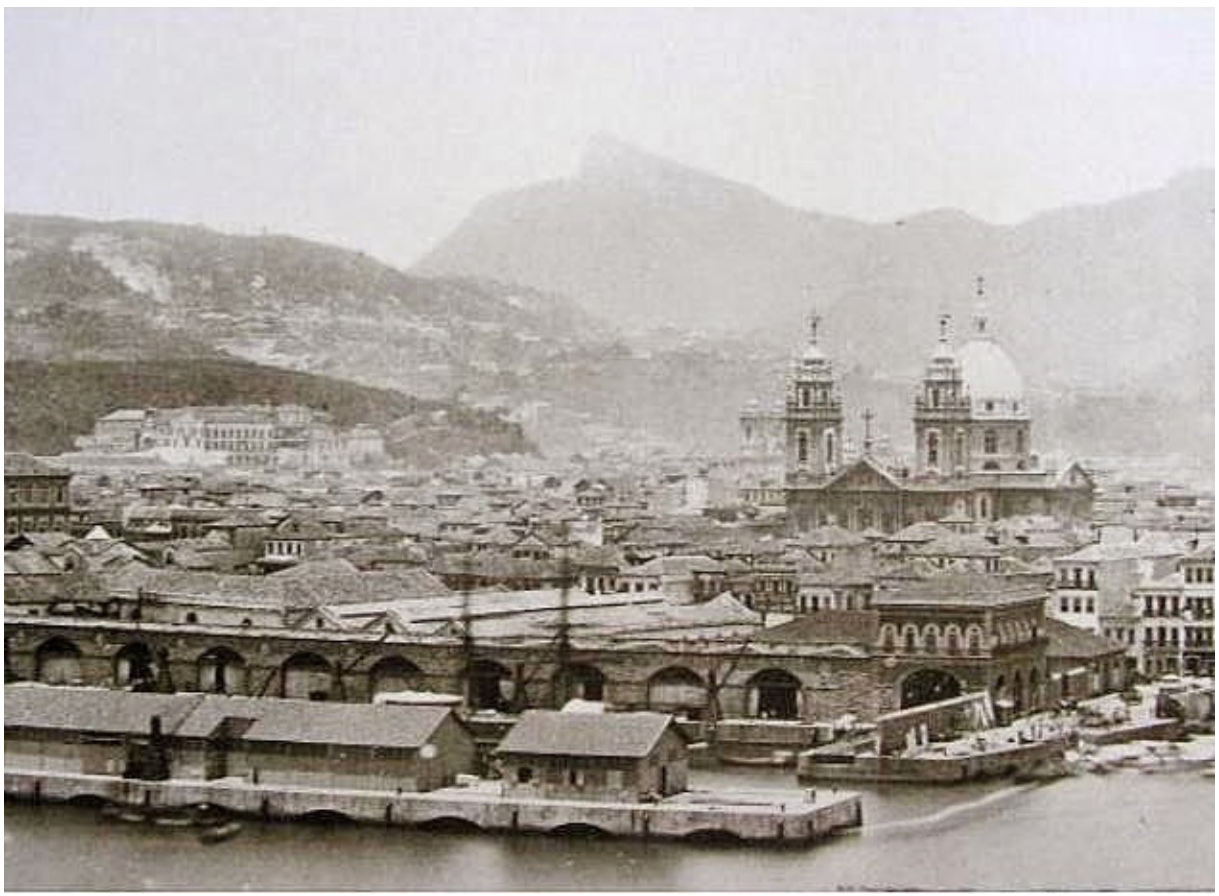

FIGURA 6

Estudo para a construção da Avenida Presidente Vargas associando

uma perspectiva da obra executada à foto aérea com demarcação da área de seu percurso a ser demolida. Sem autor.

Fonte: BUENO

E. et al. (2010, p 113) - Arquivo Geral da Cidade do Rio de Janeiro (AGCRJ).

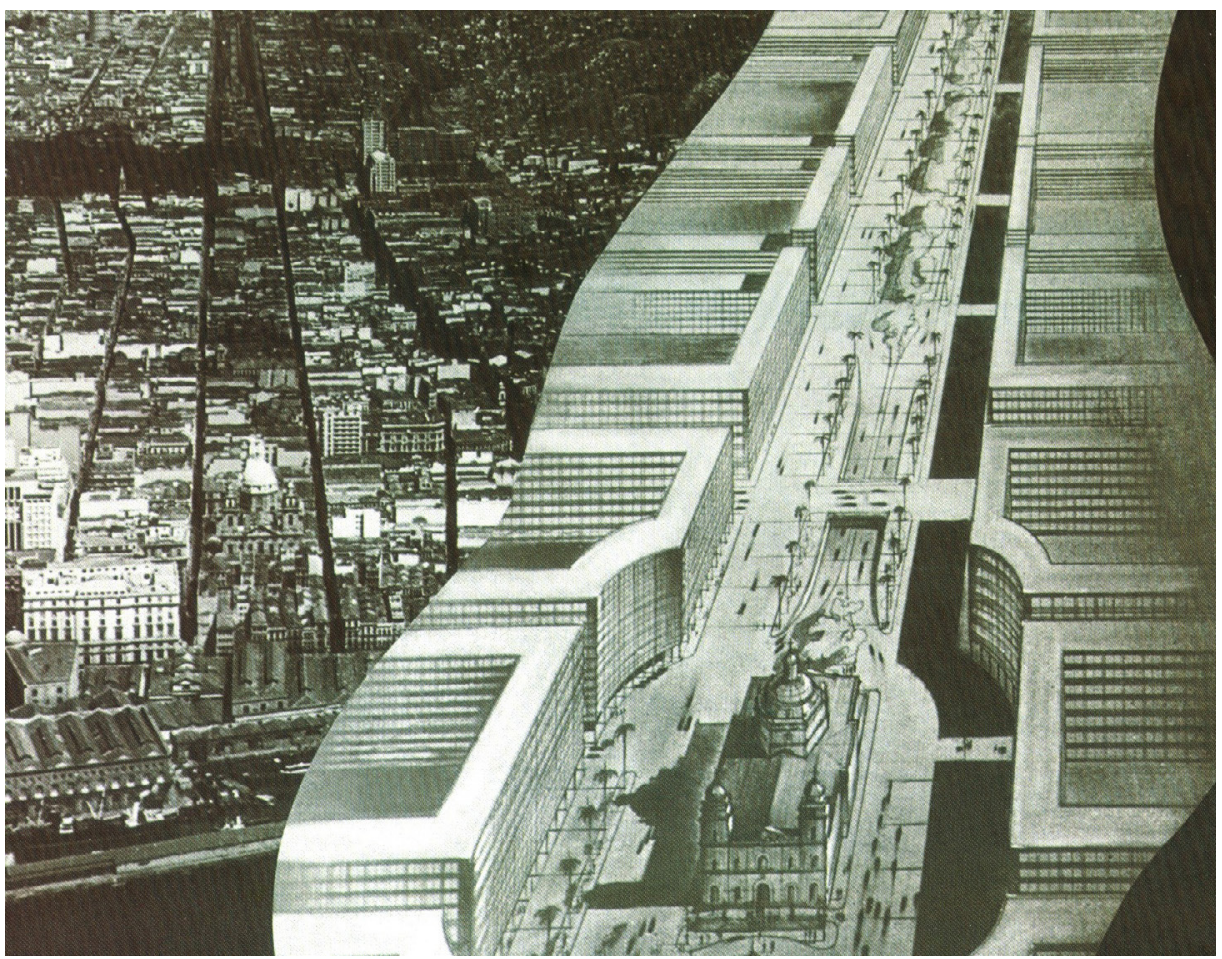


Passados mais de 60 anos de sua construção, a Avenida Presidente Vargas não se consolidou como o centro financeiro planejado nos anos 1940, tampouco exibe o skyline projetado, composto por conjunto de prédios com 22 pavimentos em ambos os lados. A ocupação prevista de fato não ocorreu em quase dois terços de seu percurso, sendo explicada por diversas restrições impostas pelo tombamento de diversos bens culturais ou pelo estabelecimento de áreas de proteção do ambiente cultural.

\section{O PÓRTICO DA QUINTA DA BOAVISTA}

Os jardins da Quinta da Boavista abrigam o antigo palácio que serviu de residência Real (1808 - 1821) e, posteriormente, imperial (1822 - 1889). Os jardins ingleses foram projetados pelo paisagista francês A. Glaziou em 1869, em reforma promovida no reinado de Pedro II. A intervenção introduziu em sua paisagem lagos, ruínas gregas, dentre outros elementos de características românticas.

O projeto de Glaziou, entre outros pontos, introduziu, a pedido de Pedro II, a Alameda das Sapucaias, um dos três elementos retilíneos dos jardins, além dos “(...) dois retângulos ao lado da edificação e um na sua parte traseira sugerindo um jardim clássico com duplo eixo de simetria”. A alameda iniciava-se e era acessada por um pórtico monumental, que tinha à frente a Praça Boavista. Com o artifício compositivo, tornou-se possível o enquadramento visual do corpo central da fachada principal do Palácio, por meio do efeito da perspectiva, reforçado pela Aleia das Sapucaias. (Figura 7) Segundo Trindade (2014, p. 63):

O Imperador solicitava uma aleia retilínea para a ligação entre a entrada principal dos jardins e o palácio - talvez em alusão às perspectivas infinitas tão presentes nos jardins barrocos, especialmente em Versailles - e Glaziou, mais interessado em conceber seus jardins com diferentes pontos de vistas como era característico dos jardins de sua época, relutava em atender ao Imperador.

A partir da proclamação da República (1889), os jardins viveram uma fase de decadência e abandono até que, no período 1907-1910 (gestão do presidente Nilo Peçanha), os jardins foram objeto de melhoramentos e modernização, sendo transformados em parque público. 
FIGURA 7

Pórtico de entrada dos jardins da quinta da Boavista no início do século $X X$, sem autor.

Fonte: <http:// rioclick.blogspot. com.br/2012/12/ sao-cristovao.html> Acesso em: 22 nov. 2016.

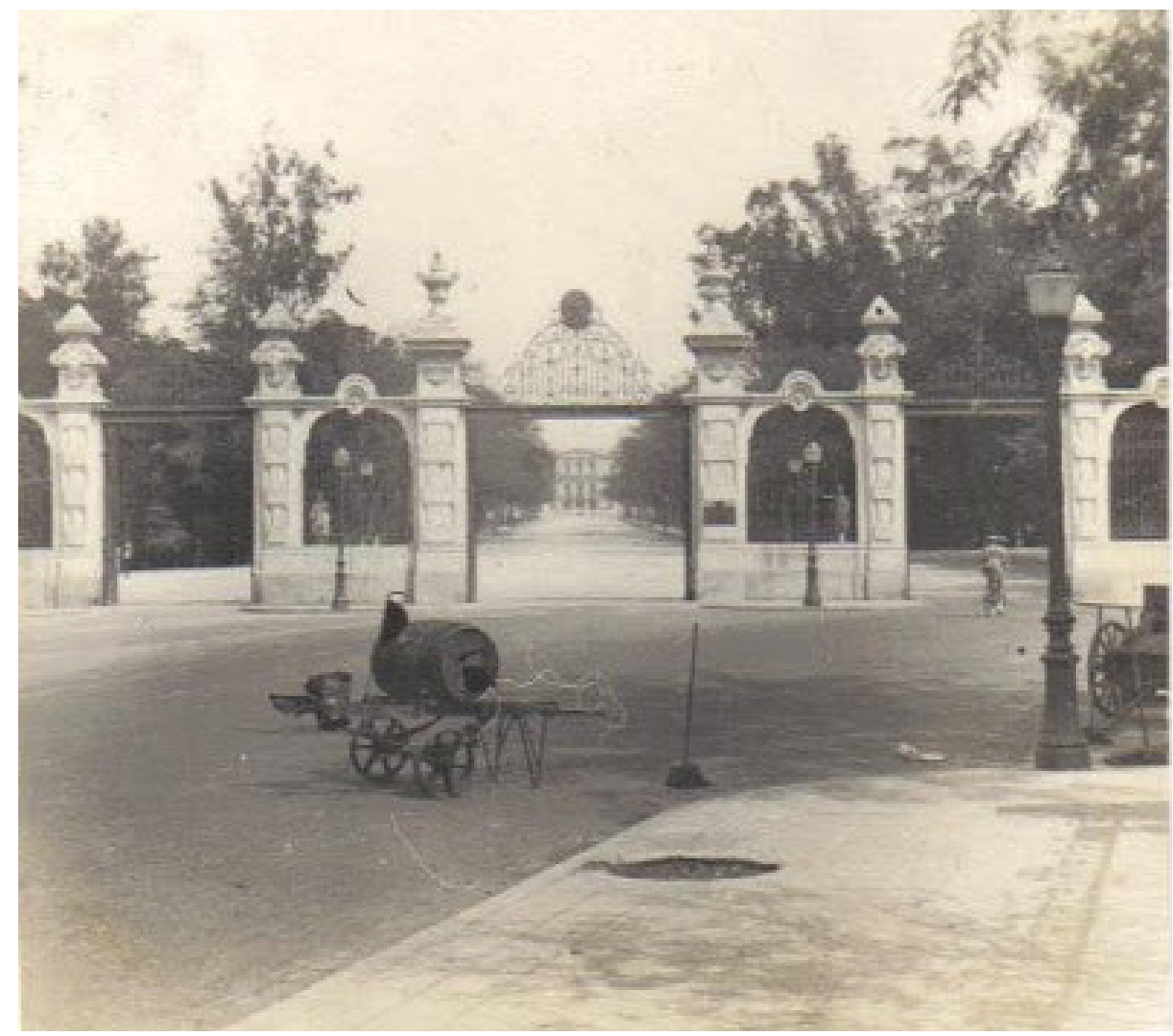

FIGURA 8

Visão atual do pórtico da Quinta da Boavista. Fonte:

$<$ http://maps google.com.br/> Acesso em: 21 nov. 2016

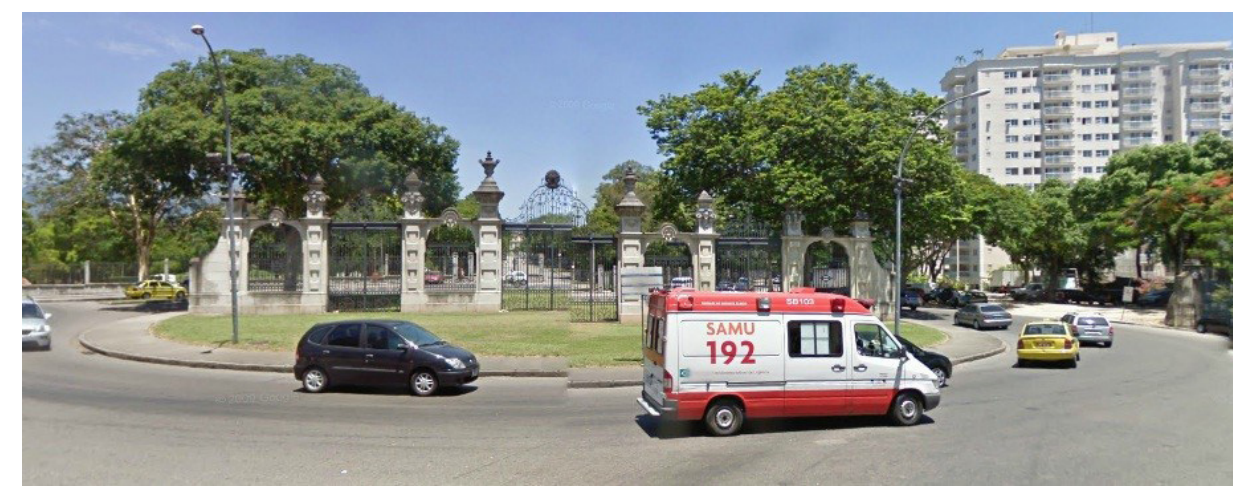




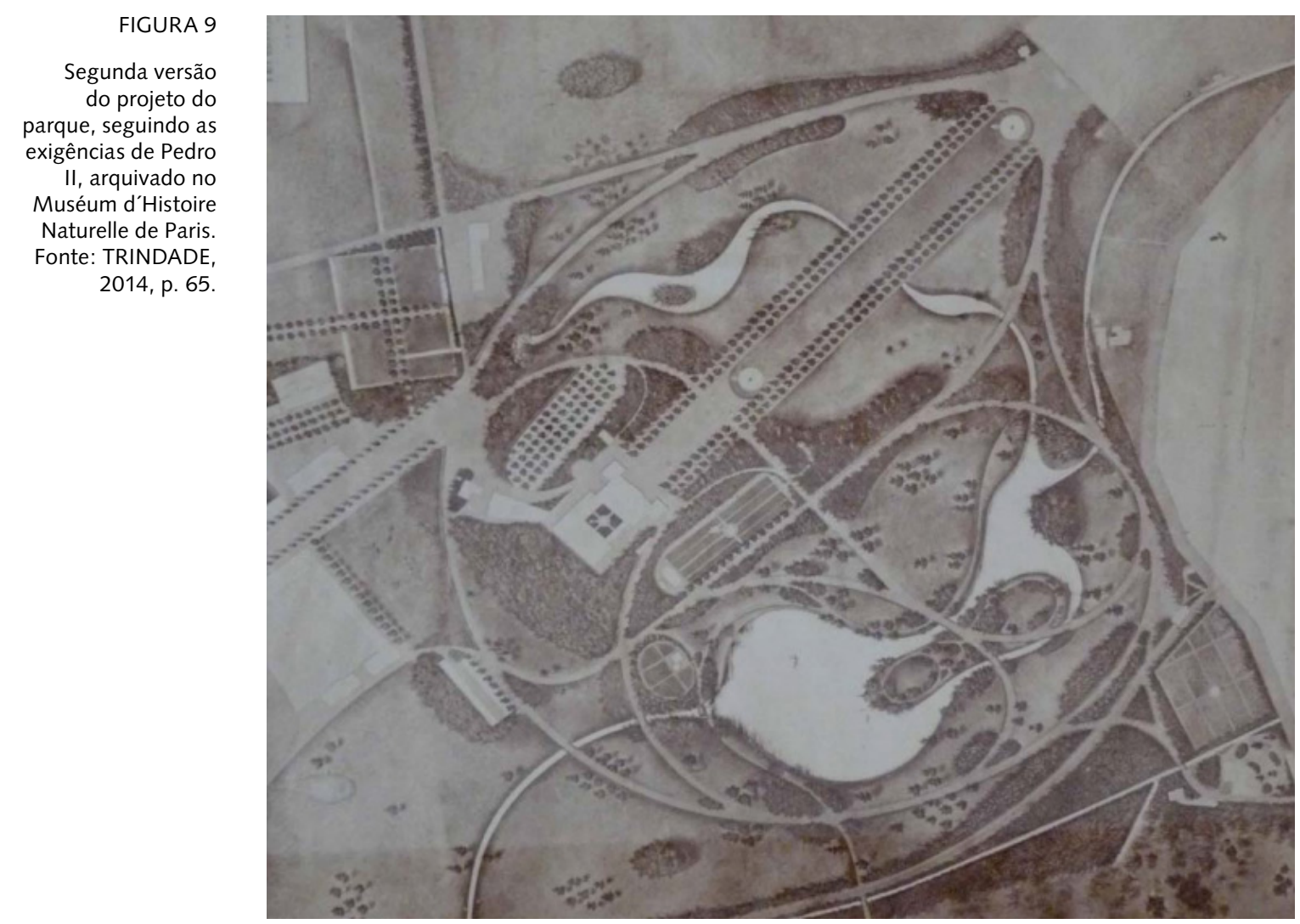

FIGURA 10

Pórtico de entrada

principal do jardim da Quinta da Boavista - São Cristóvão

Fonte: <http:// maps.google.com $\mathrm{br} />$. Acesso em: 21 nov. 2016

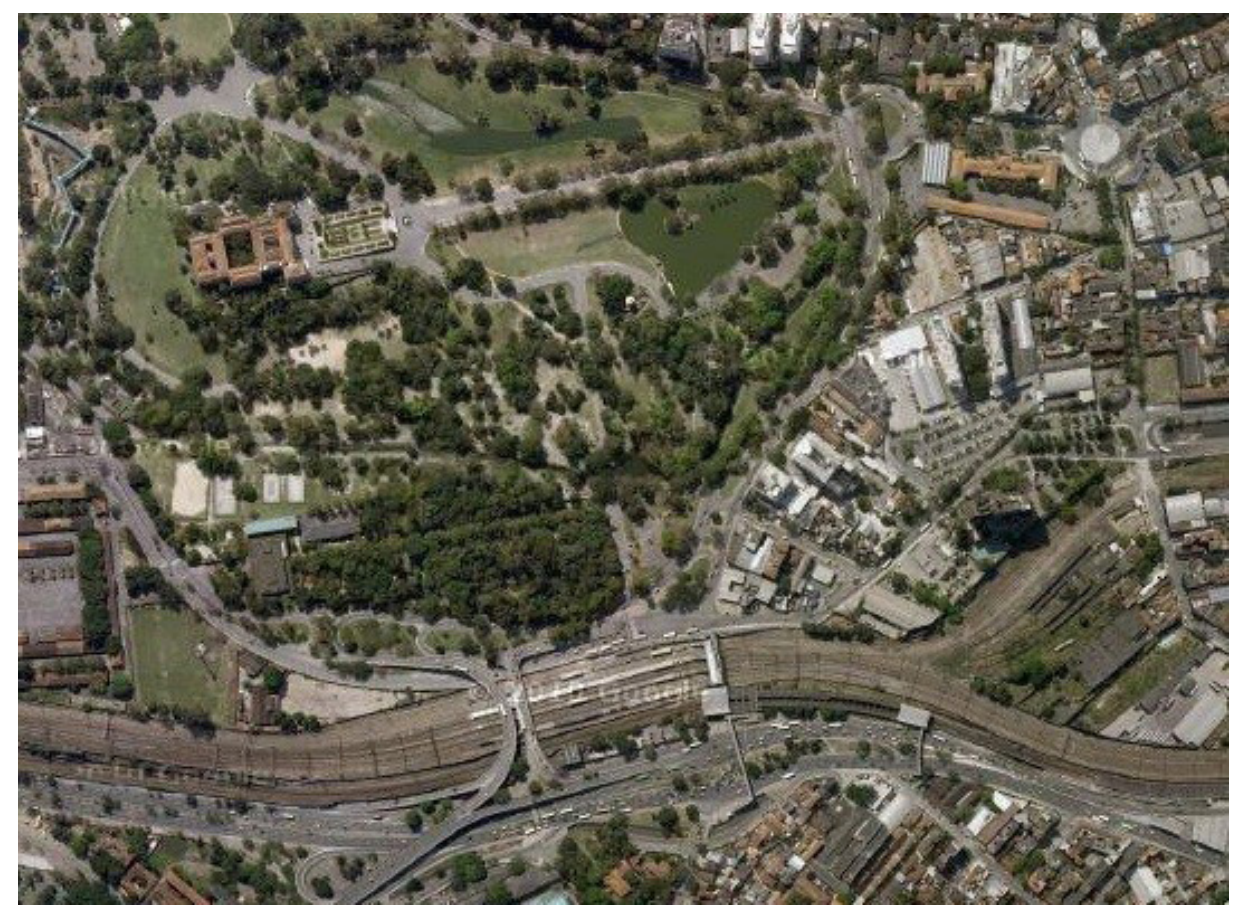


A partir deste momento, seus jardins receberam novos passeios, gradis, sanitários, mesas, jardim terraço, o Pagode Chinês, entre outros elementos paisagísticos de destaque. No entanto, a intervenção mais visível foi a remoção e consequente substituição do pórtico original de entrada por outro, de dimensões maiores, dotado de três amplos portões, encimados pelo brasão da República. Este elemento passou a marcar o fim da Rua Pedro Ivo, via pública alargada pelo Projeto de Alinhamento n. 349 (1910), além da entrada principal do novo parque cujas vias internas também possuíam função dentro do sistema viário do bairro.

Apesar de ser protegido pelo tombamento federal desde 1938, a exemplo da Igreja da Candelária, ironicamente, nos anos 1950, o monumento sofreu uma nova intervenção que lhe subtraiu parte de sua área verde em função da implantação de grande projeto viário, articulado às demais vias expressas já implantadas nas suas cercanias, construídas com o objetivo de otimizar a ligação do bairro de São Cristóvão a outras regiões da zona norte e também ao centro da cidade. Trata-se da construção da Rua General Herculano Gomes que proporcionou, com outras vias expressas, o "cintamento" dos jardins da Quinta da Boavista, por um grande anel viário, que retirou o fluxo de veículos de seu interior (Figura 10). O conjunto de vias foi integrado a mais dois viadutos e uma avenida de acesso aos bairros da zona norte, a Avenida Radial Oeste. A intervenção trouxe em seu bojo o isolamento, em uma rotunda, do pórtico de acesso principal da Quinta da Boavista, transformando-o em um mero objeto decorativo urbano, desconstruindo a unidade compositiva do projeto do Parque, proposta por Glaziou, neste trecho. Observa-se também que a função de enquadramento, por intermédio da perspectiva, anteriormente estabelecida para o pórtico de acesso principal, foi inviabilizada com a interposição de vias expressas de tráfego intenso imediatamente atrás e à frente do elemento arquitetônico (figuras 7 e 8).

Como resultados da deliberada destruição do seu contexto e funções originais, dentre outros fatores, observa-se a dificultação da leitura da paisagem e dos limites originais do Parque, por parte do observador, bem como a criação de uma "nova função" para o pórtico principal, ou seja, a “decorativa". Como diria Camillo Sitte (1992, p. 46), a intervenção realizada gerou "de fato, uma coisa muito bonita", "um portão que não se atravessa, mas em torno do qual se passeia". 


\section{CONSIDERAÇÕES FINAIS}

Os dois exemplos de monumentos localizados no Rio de Janeiro e explorados no presente trabalho ilustram com nitidez a expansão mundial da premissa projetual do isolamento de monumentos, expondo claramente seus indesejáveis efeitos urbanísticos. Eles justificam o temor expresso por Camillo Sitte, em fins do século XIX, pela uniformidade de soluções urbanísticas que de fato ocorreu após a sua morte (1903), em uma escala nunca por ele imaginada.

Observa-se uma inequívoca aproximação da sua crítica relacionada aos casos construídos nas cidades europeias de fins do século XIX, aos analisados no Rio de Janeiro, muito distante geográfica e cronologicamente. A constatação confirma a universalização das soluções projetuais e também demonstra uma total submissão do tecido urbano das cidades às premissas de planejamento racionalista, expressas detalhadamente pela Carta de Atenas (1933), apesar da existência de forte corrente teórica oposta, materializada pela outra Carta de Atenas (1931). A revisão desses princípios observada a partir da segunda metade do século XX possibilitou o resgate das premissas teóricas do documento datado de 1931, viabilizando avanços consideráveis na conservação de bens culturais que foram consolidados em documentos internacionais posteriores que influenciaram legislações urbanísticas de cidades mundiais que incluem o Rio de Janeiro.

Apesar do avanço verificado na atual legislação urbana da cidade, verifica-se um grande descompasso em relação à legislação federal, em que ainda vigora o Decreto-Lei 25/37. Em função disso, admite-se que, pelo menos no tocante aos bens tombados municipais, ao menos teoricamente, não há qualquer possibilidade de reedição de casos semelhantes aos aqui abordados, apesar de sempre pairar o perigo da distorção de seus princípios em função de interesses econômicos de grupos hegemônicos atuantes na cidade.

\section{REFERÊNCIAS}

ANDRADE, Carlos Roberto Monteiro. Apresentação. In: SITTE, Camillo. A construção de cidades segundo seus princípios artísticos. São Paulo: Ática, 1992. p. 4-6.

ARGAN, Giulio Carlo. História da arte como história da cidade. São Paulo: Martins Fontes, 1992.

BUENO, E. et al. Avenida Presidente Vargas: um desfile pela história do Brasil. Porto Alegre: Buenas Ideias; Arco, 2010.

CHOAY, Françoise. O urbanismo. São Paulo: Perspectiva, 1979. (Coleção Estudos, v. 67.) 
A alegoria do patrimônio. São Paulo: Estação Liberdade; Unesp, 2001.

Apresentação. In : RIEGL, Alois. Le culte moderne des monuments, son essence et as genèse. Paris: Éditions du Seuil, 1984.p. 8-18.

COLLINS, G. R.; COLLINS, C. C. Camillo Sitte reappraised. Londres: Mansell, 1981. (Serie Studies in History, planning and environment)

CURY, Isabelle (org). Cartas patrimoniais. Brasília: Iphan, 2004.

DUANY, Andrés. A common language of urban design. Places, A Forum of Environmental Design, n. 3, v.11, 1998.

FREIRE, A.; OLIVEIRA, L. L. (orgs). Novas memórias cariocas do urbanismo carioca. Rio de Janeiro: FGV, 2008.

GIOVANNONI, Gustavo. L'urbanisme face aux Villes anciennes. Paris: Éditions du Seuil, 1998.

LYRA, Ciro C. 'Velharias' postas abaixo: ondas de modernização sacrificaram monumentos de valor inestimável na primeira metade do século XX. Revista de História, nov. 2007. Disponível em: <http://www.revistadehistoria.com.br/secao/capa/velharias-postas-abaixo $>$. Acesso em: 4 ago. 2016.

MINDLIN, H. Modern architecture in Brazil. Nova York: Reinhold Publishing, 1956.

NORBERG-SCHULZ, Christian. Genius loci: towards phenomenology of achitecture. Nova York: Rizzoli, 1984.

PICON, Antoine. Racionalidade técnica e utopia: a gênese da Haussmannização. In: SALGUEIRO, Heliana Angotti (org). Cidades capitais do século XIX. São Paulo: Edusp, 2001.

RELPH, E. A paisagem urbana moderna. Lisboa: Edições 70, 2002.

ROSSI, Aldo. A arquitetura da cidade. São Paulo: Martins Fontes, 1984.

SANTOS, Carlos Nelson F. dos. A cidade como um jogo de cartas. Niterói: Eduff; São Paulo: Projeto, 1988.

SITTE, Camillo. A construção de cidades segundo seus princípios artísticos. São Paulo: Ática, 1992.

TELLES, Mário Ferreira de Pragmácio. Tombaram o Decreto Lei n. 25/37? Paper publicado no IV ENECULT - Encontro de Estudos Multidisciplinares em Cultura, ocorrido na Faculdade de Comunicação da Universidade Federal da Bahia (UFBA), Salvador, Bahia, 2008. gf.

TRINDADE, Jeanne Almeida da. Os jardins de Glaziou para a Quinta da Boavista, Rio de Janeiro-RJ. Revista Espaço Acadêmico, ano XIII, n. 156, maio 2014. Disponível em: $<$ http://www.periodicos.uem.br/ojs/index.php/EspacoAcademico/article/viewFile/23782/12973>. Acesso em 22 nov. 2016.

Artigo recebido em: 22/08/2016

Artigo aprovado em: 05/12/2016 